\title{
EFFECTS OF ANTIOXIDANTS ON COPPER INDUCED LIPID OXIDATION DURING SALTING OF COD (Gadus morhua L.)
}

\author{
KRISTIN LAURITZSEN ${ }^{1}$ \& RAGNAR L. OLSEN ${ }^{2}$, \\ Norwegian Institute of Fisheries and Aquaculture Ltd.. \\ ${ }^{2}$ The Norwegian College of Fishery Science, University of Tromsø.
}

Running title: Oxidation in salted cod

${ }^{1}$ To receive correspondence

Address: Muninbakken 9-13, P. Box. 6122, 9291 Tromsø, Norway.

Tlf. +4777629000

Fax. +4777629100

E-mail: kristin.lauritzsen@fiskeriforskning.no 


\begin{abstract}
A model system for studying lipid oxidation of salted cod muscle was used for investigating the interaction effects of including antioxidants and copper in the brine. The results showed that ascorbate might have pro-oxidative or anti-oxidative effects depending on the ascorbate and metal concentrations. Without added copper in the brine, concentrations of ascorbate $\leq 500$ ppm had a pro-oxidative effect. With 5 ppm copper added in the brine, low concentrations of ascorbate $(\leq 50 \mathrm{ppm})$ inhibited the formation of TBARS in the cured product. At slightly higher concentrations (100-200 ppm), the anti-oxidative properties were lost. Above 200 ppm the ascorbate reduced the oxidation level in the salt ripened product. The application of ascorbate as an antioxidant in salt curing of cod, requires the use of high concentrations $(\geq 1000 \mathrm{ppm})$ in the brine. When similar concentrations $(0.5 \mathrm{mM})$ of EDTA, citrate or ascorbate were included with 3 ppm copper in the brine, EDTA was the only antioxidant that efficiently inhibited copper-induced lipid oxidation.
\end{abstract}




\section{INTRODUCTION}

Heavily salted cod are traditional products from the North-Atlantic fisheries and are highly regarded as ripened fish products in many countries. Today, thoroughly washed split or filleted cod are usually pickle-salted or brine-cured for a short period and then salt ripened, i.e. kench cured in stacks, for at least 10 days. A major quality problem in such skin-on products is yellow/brown discoloration of the flesh surface. Seafoods containing n-3 polyunsaturated fatty acids are highly susceptible to oxidation even when the fat content is very low as in the muscle of cod fish (Dulavik et al. 1998). Lipid oxidation causes undesirable color and flavors changes and a decrease in the n-3 fatty acids that are known to be beneficial to human health. Dietary lipid oxidation products may even accelerate atherosclerotic processes, coronary heart disease (Kubow 1992) and carcineogenesis (McBrien and Slater 1982). In previous studies yellow/brown discoloration of the muscle surface was investigated in downgraded heavily salted cod fillets from a processing plant (Lauritzsen et al. 1999). The results showed that discolored areas were relatively evenly distributed on the muscle surface and that lipid oxidation correlated with the copper content in the muscle. A model system for studying lipid oxidation and yellow discoloration of salted cod muscle was established and used for investigating the effects of transition metals during the salt curing process. The study showed that the reduced form of copper is particularly pro-oxidative.

In processed food, the pro-oxidative transition metals may originate from the raw material itself or from equipment used during processing. Due to the fairly unrefined and bulk nature of solar salt most often used during salt curing, it is not always easy to comply with the limits of $0.1 \mathrm{ppm}$ copper and $10 \mathrm{ppm}$ iron in the salt. In the food industry, metal chelators are commonly used to minimize the catalytic effect of transition metals in the peroxidation process (Pokorný 1987; Løliger 1991). The most important chelators are watersoluble compounds such as citric acid, ethylenediaminetetraacetic acid (EDTA), phosphoric 
acid derivatives and some amino acids (Hølmer 1995). These function either by coordinating the metals and changing their potential by suppressing the redox reactions producing peroxyl and alkoxylradicals or by blocking complex formation with hydroperoxides and preventing their decomposition. Ascorbic acid is another commonly used water soluble antioxidant that exerts its antioxidative effect by radical scavenging via direct reaction with hydrophilic free radicals (Niki 1991) or by acting as an $\mathrm{O}_{2}$ scavenger (Klaui and Pongracz 1981). On the other hand, ascorbic acid may be a prooxidant in the presence of oxidised forms of transition metals. The effectiveness of various antioxidants appears to be influenced by either the phase of reaction systems or the type of radicals (Lin and Liang 2002). Antioxidant effects on transition metal induced lipid oxidation have been extensively studied using oils or fatty acids/proteins/polysaccharides model systems (Kanner et al.. 1977; Pokorný 1987; Harel 1994; Jacobsen 1999). Blended or intact muscle tissues are however more complex. In the present study, a model system based on brining and subsequent kench curing of fresh cod muscle was used to study the effects of ascorbate, citrate and EDTA on copper induced lipid oxidation. 


\section{MATERIALS \& METHODS}

\section{Model System}

A model system simulating normal processing conditions of salted cod was used. The cod was caught in November, June, August and September in the coastal waters of Northern Norway and had a round weight of 2 to $5 \mathrm{~kg}$. The fish was gutted, headed and stored in ice for 2-3 days before filleting and skinning. In each experiment, approximately 15-20 deboned fillets were manually cut into $1-2 \mathrm{~cm}$ cubes of muscle tissue and mixed together to minimize the variation among individuals. The cubes were brined for 5 days with a saturated salt solution (approximately $26 \%(\mathrm{w} / \mathrm{w}) \mathrm{NaCl}$ in distilled water). The saturated salt solution had added copper $(\mathrm{Cu})$ and antioxidants (ascorbate, citrate and EDTA) at different concentrations. The added copper was $\mathrm{Cu}^{2+}$ ions from a stock solution of $\mathrm{CuCl}_{2} \times 2 \mathrm{H}_{2} \mathrm{O}$ p.a., ascorbate was $\mathrm{C}_{6} \mathrm{H}_{7} \mathrm{O}_{6} \mathrm{Na}$ puriss, citrate was $\mathrm{C}_{6} \mathrm{H}_{5} \mathrm{Na}_{3} \mathrm{O}_{7} \times 2 \mathrm{H}_{2} \mathrm{O}$ p.a. and EDTA was disodium salt of EDTA, $\mathrm{C}_{10} \mathrm{H}_{14} \mathrm{~N}_{2} \mathrm{Na}_{2} \mathrm{O}_{8} \times 2 \mathrm{H}_{2} \mathrm{O}$ p.a.. Subsequently, the cubes were removed from the brine, drained for 30 seconds and kench cured for 16 days using solid $\mathrm{NaCl}$ in a weight ratio of 1 part fish and 2 parts salt. No antioxidants or metals were included during the kench curing. The temperature during the experiments was $8-10^{\circ} \mathrm{C}$. All chemicals used for brine preparations, dry salting and chemical analyses were obtained from Merck, Darmstadt, Germany.

The effect of increasing ascorbate concentration in the brine on copper induced lipid oxidation was investigated in an experiment, as described above, using $200 \mathrm{~g}$ muscle cubes and $1600 \mathrm{~g}$ saturated salt solution for each ascorbate concentration. The fish was caught in June, August and September and the post rigor $\mathrm{pH}$ of the fillets was in the range of 6.42-6.72 and the $\mathrm{pH}$ of the brines containing ascorbate with or without copper, was in the range of 6.31 to 6.59 prior to salting. To the brines were added 0 or $5 \mathrm{ppm}$ of $\mathrm{Cu}^{2+}$ and $0,10,30,50,100$, $200,500,1000,2000,5000,7000$ or $10000 \mathrm{ppm}(\mathrm{w} / \mathrm{w})$ ascorbate. The experiments were replicated two times for each ascorbate concentration. Lipid oxidation as 2-thiobarbituric acid 
reactive substances (TBARS) and instrumental yellow color Chromameter (Minolta Camera Co. Ltd., Osaka, Japan) of salted muscle cubes were determined after 21 days.

The effect of using different antioxidants in the brine on copper induced lipid oxidation was studied as described using $1400 \mathrm{~g}$ muscle cubes and $5000 \mathrm{~g}$ saturated brine for each brine combination. The fish was caught in June and November and the post rigor $\mathrm{pH}$ of the fillets was in the range of 6.52 to 6.73 and the $\mathrm{pH}$ of the brines containing antioxidant with or without copper was in the range of 5.25 to 5.66 prior to salting. To the brines were added 0 or $3 \mathrm{ppm} \mathrm{Cu}^{2+}$ and $100 \mathrm{ppm}$ ascorbate, $150 \mathrm{ppm}$ citrate or $193 \mathrm{ppm}$ of EDTA giving approximately $0.5 \mathrm{mM}$ antioxidant in the respective brines. The experiments were carried out twice for each type of antioxidant. Lipid oxidation as TBARS and instrumental yellow color, muscle $\mathrm{pH}$, copper, $\mathrm{NaCl}$ and water contents of the muscle cubes were determined after 0 , $0.5,1,2,3,4,5$ and 21 days of salting.

\section{Analyses}

Lipid oxidation and the chemical analysis were performed on pooled muscle samples. The pooled samples were prepared by mincing the muscle cubes in a Dito Sama (K55) Food Processor (Abusson, France) for approximately $1 \mathrm{~min}$. The samples were either analyzed immediately (Instrumental yellow color and muscle $\mathrm{pH}$ ) or packed in sealed plastic bags and stored for 1 to 4 weeks at $-80 \mathrm{C}$ before analysis.

Samples were either taken at the start ( 0 days) and during the brining period $(0,0.5,1,2$, $3,4,5$ days) or at the end of the salting process (21 days). At each sampling, 50-100 $\mathrm{g}$ of muscle cubes (approximately 25 - 50 pieces) were removed and homogenized as described above.

Lipid oxidation was estimated by determining the amount of TBARS in an aqueous trichloroacetic acid extract (Witte et al. 1970) as described previously (Dulavik et al. 1998). Two replicate extractions were made for each pooled sample of muscle cubes. Instrumental 
yellow color of the cured muscle mince was determined using a Minolta Chromameter, CR200. The detector was placed on the surface of the plastic bag containing muscle mince, at four different areas of the sample recording the $\mathrm{L}^{*} \mathrm{a}^{*} \mathrm{~b}^{*}$ modus, obtaining a mean value.

The concentrations of copper in the muscle were determined after wet digestion; i.e. minced muscle, $8-10 \mathrm{~g}$, was boiled in $25 \mathrm{~mL} \mathrm{HCl}(25 \% \mathrm{~V} / \mathrm{V})$. The metals were analyzed by flame atomic-absorption spectrometry as described by Simpson and Blay (1966) using a Perkin Elmer 3110 spectroscope (Perkin Elmer Co. Ltd., Norwalk, CT). Standards of copper and iron (Titrisol, Merck, Darmstadt, Germany) were also diluted in 25\% (w/w) $\mathrm{HCl}$. Three replicates for each pooled muscle sample were made. The mean and standard deviation were calculated from these values.

The $\mathrm{pH}$ of fresh muscle tissue was measured in a $1: 1$ mixture of muscle homogenate and $0.15 \mathrm{M} \mathrm{KCl}$, while the $\mathrm{pH}$ of salted muscle was recorded after mixing the muscle homogenate with 5 parts of distilled water. The $\mathrm{pH}$ of the brines prior to salting was measured in a $1: 4$ dilution of the brine homogenate with distilled water. A PHM 80 Radiometer (Copenhagen, Denmark) with a glass electrode was used and $3-6$ replicates of each sample were made to obtain a mean value. Two or three replicates of each sample were analyzed.

The water content of the muscle samples was determined by drying to a constant weight at 105C (AOAC [950.46] 1990) and the $\mathrm{NaCl}$ content was determined by the standard procedure (AOAC [937.09] 1990). Three replicates of each sample were analyzed for water and salt determinations.

Statistical analysis of the analytical data from muscle samples was performed on the software program SAS version 6.12 (SAS Institute, Cary, NC). Data were subjected to oneway analysis of variance (ANOVA) by using the general linear model procedure. Where statistical differences were noted for a measurement, differences among sample means were 
determined using the Tukey's Multiple comparison test. The level of significance was set at $p$ $=0.05$ for all tests.

\section{RESULTS}

\section{Effects of increasing concentration of ascorbate in the brine}

A model system consisting of small muscle cubes of fresh cod and brines simulating normal processing conditions was used to study copper-induced lipid oxidation. Figure 1 shows the effects of an increasing ascorbate concentration when the model system was used without addition of copper in the brine. An ascorbate concentration of $<500 \mathrm{ppm}$ in the brine induced lipid oxidation as reflected in both TBARS and instrumental $b^{*}$ values of the salt ripened product. At 1000 ppm ascorbate or higher, no pro-oxidant activity could be detected. The TBARS value at this concentration was actually lower than in the samples without ascorbate added.

Figures $2 \mathrm{a}$ and $\mathrm{b}$ show the TBARS and instrumental yellow color $\left(\mathrm{b}^{*}\right)$ values of kench cured cod muscle cubes brined in saturated sodium chloride solution containing a fixed

$\mathrm{Cu}^{2+}(5 \mathrm{ppm})$ and different concentrations of ascorbate $(10-2000 \mathrm{ppm})$. With $5 \mathrm{ppm} \mathrm{Cu}^{2+}$ and no antioxidant added, the TBARS values were approximately $280 \mathrm{nmol} \mathrm{MDA} / \mathrm{g}$ after 21 days of curing (Fig 2a). When the ascorbate concentration increased from 0 to $50 \mathrm{ppm}$, the TBARS values decreased to approximately $40 \mathrm{nmol} \mathrm{MDA} / \mathrm{g}$, indicating antioxidative effects on copper-induced lipid oxidation in the product. However, further increase in the concentration of ascorbate to $100 \mathrm{ppm}$, sharply raised the TBARS values to approximately the same level as found when no ascorbate was added. Higher concentrations of ascorbate present during the initial period inhibited the formation of copper induced TBARS (Fig 2b). With 1000 ppm the lowest value of oxidation products was reached. In general, the results of the instrumental yellow color $\left(b^{*}\right)$ measurements followed the TBARS values. However, with the lowest 
concentrations of ascorbate (10-30 ppm) $b^{*}$ values appeared to be constant or increasing instead of decreasing as the TBARS did.

\section{Effects of including different antioxidants during brining}

The effects of including three different antioxidants; EDTA, citrate and ascorbate, in the brine on copper induced lipid oxidation were studied using the model system described earlier. In these experiments, the copper concentration in the brines was $3 \mathrm{ppm} \mathrm{Cu}^{2+}$ while the concentrations of the antioxidants were in the range of 100 to $193 \mathrm{ppm}(0.5 \mathrm{mM})$. Muscle cubes were sampled at the start (day 0), during the brining period (days 1-5) and at the end of kench curing (day 21). Lipid oxidation was measured as TBARS values and instrumental yellow color values $\left(b^{*}\right)$ and the results are presented in Figures $3 a$ and $b$, respectively. The three antioxidants had clearly different effects on the TBARS of the salt ripened products after 21 days of curing. Only EDTA inhibited copper induced lipid oxidation giving a TBARS value of 15 compared to $111 \mathrm{nmol} \mathrm{MDA} / \mathrm{g}$ in the samples brined with only copper added to the brine. The TBARS values in the EDTA samples were actually in the same range as in samples not oxidized with copper. Citrate on the other hand, accelerated copper induced lipid oxidation in the cured muscle tissue producing TBARS values approximately 1.5 times higher than in the samples brined with only $\mathrm{Cu}^{2+}$ added to the brine. Ascorbate appeared not to have any effect on the copper induced lipid oxidation, giving TBARS values of $94 \mathrm{nmol} \mathrm{MDA} / \mathrm{g}$ of the salt ripen product. The presence of antioxidants inhibited copper induced oxidation during the brining period. However, at the end of the brining period (day 5) the citrate samples showed TBARS values of $23 \mathrm{nmol} \mathrm{MDA} / \mathrm{g}$, indicating enhanced copper-induced lipid oxidation.

Instrumental yellow color values $\left(b^{*}\right)$ of the minced muscle samples were also analyzed as a measure of copper-induced lipid oxidation in the cured muscle (Figure 3b). In 
general, the $b^{*}$ values of the salt ripened products followed the TBARS values, except that of the ascorbate samples which had $b^{*}$ values significantly $(\mathrm{p}<0.05)$ higher than the samples with only $\mathrm{Cu}^{2+}$ added in the brine, after 21 days of salting.

To determine if the presence of antioxidants in the brine could affect the absorption of copper ions from the brine and into the muscle, the concentration of the metal was determined in the muscle samples during the brining process and in the salt ripened products (Figure 4). The uptake of copper ions was significantly $(p<0.05)$ affected by the different antioxidants. The copper content of the EDTA samples increased just slightly during the brining period. During most of the process, it was lower than the content of the samples brined with only $\mathrm{Cu}^{2+}$ added. The copper content of the EDTA samples approached its maximum of 5-6 ppm during the first day of brining. On the other hand, the copper content of the citrate samples increased more rapidly during the brining period and ended at a significantly $(p<0.05)$ higher level than the EDTA samples. The final copper concentration of the citrate samples was lower than the concentration of the salt ripened samples brined with only copper added. The copper content of the ascorbate samples increased less rapidly than in the citrate samples during the brining but appeared significantly higher than in all other muscle samples after 21 days of curing. The copper content of the control samples i.e. samples brined without any additives, decreased slightly during the first day of brining and remained at this level during the rest of the curing process.

In our previous study, it was indicated that copper induced lipid oxidation increased by a low post rigor muscle-pH prior to heavy salt curing. The $\mathrm{pH}$ of the muscle was therefore determined at start, during the brining and at the end of the curing process. It can be seen that the $\mathrm{pH}$ of the EDTA samples remained at a significantly higher level than those of the citrate samples during salt curing (Figure 5a). The muscle-pH decreased rapidly from 6.65 in fresh muscle to values in the range of 6.1 to 6.2 during the first day of brining. Further on in the 
curing process, the muscle-pH decreased just slightly (0.1-0.2). After 21 days of curing the range of the muscle-pH values varied from 5.9 to 6.1 , with the citrate samples at the lower level (5.93) and the EDTA samples at the upper level (6.13). Prior to salting, the pH of the brines were: control, 5.32; $\mathrm{Cu}^{2+}, 5.33 ; \mathrm{Cu}^{2+}$ and citrate, 5.66; $\mathrm{Cu}^{2+}$ and ascorbate, 5.25 and $\mathrm{Cu}^{2+}$ and EDTA, 5.50.

Conformational changes of the proteins, protein aggregation and losses of water are all processes taking place during salt curing. The water content of the muscle samples was therefore determined initially, during the brining, and at the end of the curing process as shown in Figure $5 \mathrm{~b}$. The water content was reduced from $83 \%$ in fresh muscle to values in the range of 69 to $72 \%$ after one day of brining. During the remaining brining period, the water content of the citrate samples decreased to a significantly $(\mathrm{p}<0.05)$ lower level than the EDTA and ascorbate samples. After 21 days of curing, the three antioxidants had clearly different effects $(p<0.05)$ on the water contents of the muscle samples. The highest water content was found in the EDTA samples $(66.9 \%)$ and lowest value in the citrate samples $(60.6 \%)$.

The $\mathrm{NaCl}$ concentration of the muscle samples was also determined inititally, during the brining, and at the end of the curing process as shown in Figure $5 \mathrm{c}$. It can be seen that the $\mathrm{NaCl}$ content increased rapidly from $0.15 \%$ in fresh muscle to concentrations in the range of 15 to $17 \%$ during the first 12 hours of the brining. At the end of the brining process and after salt ripening, the $\mathrm{NaCl}$ concentrations of the muscle were in the range of 17.6 to $18.2 \%$ and 18.6 to $22.7 \%$, respectively. The samples with lowest water content such those brined with citrate, had the highest $\mathrm{NaCl}$ content during the brining process. At the end of the curing, the samples brined without additives had the highest $\mathrm{NaCl}$ concentration followed by the citrate samples. 


\section{DISCUSSION}

\section{Effects of increasing ascorbate concentration in the brine}

The model system simulating normal production of salted cod was used to investigate the interaction effects of ascorbate and copper ions in the brine and the effects of ascorbate alone on lipid oxidation in salt ripened products. The results clearly showed that asorbate used during production of heavily salted cod might have pro-oxidative or antioxidative effects depending on the ascorbate and metal concentrations. Without added copper in the brine, concentrations of $\leq 500 \mathrm{ppm}$ ascorbate had a prooxidative effect on the cured product. This pro-oxidative effect is often explained by the ability of ascorbate to reduce endogenous transition metals. Reduced transition metals are known to be particularly pro-oxidative (Haase and Dunkley 1969a and b; Kanner et al. 1977; Frankel 1998). We suggest that at higher concentrations $(\geq 1000 \mathrm{ppm})$, ascorbate are able to reduce hydroperoxide radicals formed by the reduced metals. In addition, it is known that ascorbate is able to chelate transition metals thereby inactivating them (Khan and Martell 1967; Kanner et al. 1977). The concentrations we found to be pro-oxidative and those found anti-oxidative, are in accordance with the findings of Ramanathan and Das (1993) studying the effect of ascorbate on steam-cooked ground fish and of Deng et al. (1978) studying the effect of ascorbate on cold stored mullet.

With 5 ppm copper added in the brine, increasing concentration of ascorbate resulted in different lipid oxidation levels. When no ascorbate was included in the brine, the salt ripened product had, as expected, a high oxidation level measured both as TBARS and instrumental yellow color ( $\left.\mathrm{b}^{*}\right)$ (Lauritzsen et al. 1999). Under such pro-oxidative conditions the presence of relatively low concentrations of ascorbate $(\leq 50 \mathrm{ppm})$ inhibited the formation of malondialdehyd-bis(diethylacetal)-like substances in the cured product. The explanation for this may be that ascorbate functions mainly as a radical scavenger. At higher concentrations (100-200 ppm) the antioxidative properties are lost and pro-oxidative effects 
may even be present (Figure 2a and b). One plausible explanation for this may be that the ascorbate concentration must increase to a critical level before it reduces the transition metals. The antioxidative properties of ascorbate at higher levels may be explained as described earlier. These results appear similar to those obtained by Haase and Dunkley (1969a and b) and Kanner et al. (1977) who studied oxidation in a potassiumlinoleate and in a $\beta$-carotenelinoleate model system, respectively, and found pro-oxidative effects with low copper and high ascorbic acid concentrations. As copper concentrations were raised in these investigations antioxidative effects were found. On the basis of the present results, we may conclude that application of ascorbate as an antioxidant in salt curing of cod, requires the use of high concentrations $(\geq 1000 \mathrm{ppm})$ in the brine.

\section{Effects of including different antioxidants during brining}

The effects of added EDTA, citrate and ascorbate in the brine on copper-induced lipid oxidation were studied by the same model system. At concentrations used, EDTA was the only effective antioxidant while citrate behaved as a pro-oxidant. EDTA is a chelator that forms thermodynamically stable complexes with transition metal ions inhibiting electron transfer and thus oxidation (Pribil 1972; Pokorný 1987). The spatial structure of the anion of EDTA, which has six donor atoms, allows it to satisfy the coordination number of six frequently encountered among metal ions. The effectiveness of EDTA in inhibiting copperinduced lipid oxidation has been shown in several studies. Examples are inhibition of the development of off-flavour in margarines during storage (Melniek 1962), inhibition of copper induced rancidity in cod muscle blends at $12 \% \mathrm{NaCl}$ concentrations (Castell et al. 1965) and inhibition of metal-induced lipid oxidation of fish oil enriched mayonnaise products (Jacobsen and Timm 2001). 
Citric acid is a weaker chelating agent than EDTA. The lack of antioxidative effects, are probably caused by a relatively low citrate concentration compared to the amount of copper. Reports have suggested that a very high ratio of citric acid to copper is needed (Castell et al. 1965; Flider and Orthoeffer 1981; Aubourg et al. 2003;). It is also tempting to suggest that the high $\mathrm{NaCl}$ concentration may have contributed to loss of chelating properties of the antioxidant. The results in this experiment, using ascorbate at $100 \mathrm{ppm}$ in the brine, confirmed the high lipid oxidation found in salt ripened product in the experiments described earlier. The lower TBARS level is probably caused by the use of $3 \mathrm{ppm}$ copper in the second experiments (Fig. 3a and b) while 5 ppm was used in the first experiments (Fig. 2a and b). During most of the brining period (day 0-4) it was noticed that the TBARS values in all samples treated with anti-oxidants were lower than in the samples brined with only copper. It was surprising to find that citrate gave such low values initially particularly since it also appeared to facilitate the absorption of copper into the muscle (Fig. 4). In salt cured cod we have previously shown that lipid oxidation, measured as TBARS correlated with the yellow color of the product (Lauritzsen et al. 1999). In general, the results in Figures 3a and b confirmed these results.

The results indicated that the uptake of copper into the muscle was influenced by the antioxidant added during brining. EDTA appeared to retard the absorption of copper ions from the brine into the muscle. The main reason for its effectiveness as an antioxidant is, however, suggested to be due to its chelating properties. In addition to its ineffectiveness as an antioxidant, citrate stimulated the uptake of copper into the muscle. The reason why citrate appeared to facilitate the uptake of copper is not known. One can speculate that the binding of copper to citrate neutralizes the positive charge of the metal and thereby makes it easier to penetrate into the muscle (Goldstein and Czapski 1986; Kanner 1994). At the end of the curing the increased copper concentration observed in some of the samples could be explained by the loss of moisture during kench curing. 
Normally, salt curing induces conformationl changes in the proteins and a reduction in the muscle pH is observed (Lauritzsen et al. 1999; Thorarinsdottir 2001). As expected, the results with antioxidants included in the brine also showed that the muscle-pH decreased by heavy salt curing. In our previous study, it was indicated that the copper induced lipid oxidation increased by low $\mathrm{pH}$ of the fish muscle post rigor (Lauritzsen et al. 1999). In the present study we found that the citrate samples, the samples with the highest lipid oxidation, had the lowest $\mathrm{pH}$ (Fig. 5a). Recent reports have shown that $\mathrm{pH}$ affected lipid oxidation of washed cod muscle when trout hemolysate was used as a catalyst (Richards and Hultin 2000). The level of pro-oxidative deoxyhemoglobin was found to sharply increase with $\mathrm{pH}$ reduction from 7.6 to 6.0 (Richards et al. 2002). However, in heavy curing of cod this mechanism is probably not relevant since the level of hemoglobin is very low in light muscle of cod. The reduction in the $\mathrm{pH}$ of the EDTA samples appeared to occur more slowly than in other samples. The binding of the EDTA to proteins may contribute to this (Hamm 1960).

The samples brined with citrate showed lower water contents than other samples (Fig. 5b). It has been reported earlier that the ultimate water content of cured meat muscle depends mainly on the $\mathrm{NaCl}$ concentration and the $\mathrm{pH}$ of the brine (Hamm 1960). It is well known that heavy salt curing causes denaturation of the muscle proteins due to "salting-out" effects (von Hippel and Schleich 1969). Although the brine with citrate added had a slightly higher $\mathrm{pH}$ value than the other brines, the $\mathrm{pH}$ of the cured muscle was among the lowest. The low water content may be explained by increased "salting out" effects of the muscle proteins due to a lower $\mathrm{pH}$. Conversely, it is also known that enhanced interactions between muscle proteins and lipid oxidation end products, lead to protein denaturation and subsequently dehydration (Mackie 1993; Howell 1995; Li and King 1996; Badii and Howell 2002).

The lowered water content of the citrate samples was thought to be explained by an increased uptake of $\mathrm{NaCl}$. The $\mathrm{NaCl}$ content was therefore monitored during the experiments 
(Figure 5c). As expected, the salt content changed inversely with the water content due to large osmotic forces. A slightly higher $\mathrm{NaCl}$ content in the citrate samples during the brining period compared to the other samples was observed. However, this may not explain all the existing differences in the water content and lipid oxidation level between the samples brined with anti-oxidants.

The results from this work demonstrated that EDTA was the only antioxidant/chelator that efficiently inhibited copper-induced lipid oxidation of the final cured product. Further investigations are required on how the use of antioxidants during heavy curing of cod can minimize problems associated with lipid oxidation and discoloration.

\section{ACKNOWLEDGMENTS}

This work was financed by the Norwegian research Council. 


\section{REFERENCES}

AUBOURG, S.P. 2003. Effect of citric acid on rancidity development in horse mackerel

(Trachurus trachurus) during frozen storage. ISBN 9979-74-005-1, pp. 145-146. Poster presented at the First Joint Trans-Atlantic Fisheries technology Conference- TAFT 2003-08-19 $33^{\text {rd }}$ WEFTA and $48^{\text {th }}$ AFTC meetings, Reykjavik- Iceland.

BADII, F. and HOWELL, N.K. 2002. Effect of antioxidants, citrate and cryoprotectants on protein denaturation and texture of frozen cod (Gadus morhua). J. Agric. Food Chem. 50, 2053-2061.

CASTELL, C.H., MACLEAN, J. and MOORE, B. 1965. Rancidity in Lean Fish Muscle. IV. Effect of Sodium Chloride and Other Salts. J. Fish. Res. Bd. Canada 22, 929-944.

DENG, J.C., WATSON, M., BATES, R.P. and SCHROEDER, E. 1978. Ascorbic acid as an antioxidant in fish flesh and its degradation. J. Food Sci. 43, 457-460.

DULAVIK, B., SØRENSEN, N.K., BARSTAD, H., HORVLI, O. and OLSEN, R.L. 1998. Oxidative stability of frozen light and dark muscles of saithe (Pollachius virens L.). J. Food Lipids 5, 233-245.

FLIDER, F.J. and ORTHOEFFER, F.T. 1981. Metals in soybean oil. J. Am. Oil Chem. Soc. $58,270-272$.

FRANKEL, E.N. 1998. Lipid oxidation. The Oily Press Ltd. Dundee. Printed at Bell and Bain Ltd. Glasgow, Scotland.

GOLDSTEIN, S. and CZAPSKI, G. 1986. The role and mevhanism of metal ions and their complexes in enhancing damage in biological systems or in protecting these systems from the toxicity of $\mathrm{O}_{2}^{-}$. Free Rad. Biol. and Med., 2, 3-11.

HAASE, G. and DUNKLEY, W.L. 1969a. Ascorbic acid and copper in linoleate oxidation. 2. Ascorbic acid and copper as oxidation catalysts. J. Lipid Res. 10, 561-567. 
HAASE, G. and DUNKLEY, W.L. 1969b. Ascorbic acid and copper in linoleate oxidation .

3. Catalysts in combination. J. Lipid Res. 10, 568-576.

HAMM, R., 1960. Biochemistry of meat hydration. Adv. Food Res. 10, 355-463.

HAREL, S. 1994. Oxidation of ascorbic acid and metal ions as affected by NaCl. J. Agric. Food Chem., 42, 2402-2406.

HOWELL, N. 1995. Interaction of proteins with small molecules. In: Ingrediant InteractionsEffects on Food Quality, (A. Gaoucar, ed.) pp 269-289. Marcel Dekker, New York. HØLMER, G. 1995. Antioxidative systems, with special regard to membranes. In Fish quality-role of biological membranes, Proceeding from the meeting $23^{\text {rd }}$ and $24^{\text {th }}$ of March at Hillerød, (F. Jessen ed.) pp 117-128. TemaNord Nordic Council of Ministers: 624, ISBN 929120771 3, Copenhagen, Denmark.

JACOBSEN, C. 1999. Effect of ascorbic acid on iron release from the emulsifier interface and on the oxidative flavour deterioration in fish oil enriched mayonnaise. J. Agric. Food Chem. 47, 4917-4926.

JACOBSEN, C. and TIMM, M. 2001. Oxidation in fish oil enriched mayonnaise: ascorbic acid and low pH increase oxidative deterioration. J. Agric. Food Chem. 49, 3947-3956. KANNER, J., MENDEL, H. and BUDOWSKI, P. 1977. Prooxidant and antioxidant effects of ascorbic acid and metal salts in a $\beta$-carotene-linoleate model system. J. Food Sci. 42, 60-64.

KANNER, J. 1994. Oxidative processes in meat and meat products: Quality implications. Meat Sci. 36, 169-189.

KHAN, T.M.M and MARTELL, A.E. 1967. Metal ion and metal chelate catalysed oxidation of ascorbic acid by molecular oxygen. 1. cupric and ferric ion catalysed oxidation. J. Am. Chem. Soc. 89, 4176. 
KLÄUI, H. and PONGRACZ, G. 1981. Ascorbic acid and its derivates as antioxidants in oils and fats. In Vitamin C, Ascorbic Acid, (J.N. Consell and D.H. Horning, eds.) pp 139166. Applied Science Publishers, London, UK.

KUBOW, S. 1992. Routes of Formation and Toxic Consequences of Lipid Oxidation Products in Foods. Free Rad. Biol. Med. 12, 63-81.

LAURITZSEN, K., MARTINSEN, G. and OLSEN, R.L. 1999. Copper induced lipid oxidation during salting of cod (Gadus morhua L). J. Food Lipids 6, 299-315.

LI, S.J. and KING, A.J. 1996. Lipid oxidation and myosin denaturation in dark chicken meat. J. Agric. Food Chem. 44, 3080-3084.

LIN, C.C. and LIANG, J.H. 2002. Effect of antioxidants on the oxidative stability of chicken breast meat in a dispersion system. J. Food Chem. Toxiol. 67(2), 530-533.

LÖLIGER, J. 1991. The use of antioxidants in foods. In: Free Radicals and Food Additives, (O.L. Arouma and B. Halliwell, eds.) pp. 121-150. Taylor and Francis, London, UK. MACKIE, I.M. 1993. The effects of freezing on flesh proteins. Food Rev. Int., 9, 575-610. McBRIEN, D.C.H. and SLATER, T.F. 1982. Lipid peroxidation and activated intermediates. In Free Radicals, Lipid Peroxidation and Cancer, (D.C.H. McBrien and T.F. Slater, eds.) pp. 101-439. Academic press, New York, NY.

MELNIEK, D. 1961. Flavor stabilized salted margarine and process of producing the same. US Patent 2, 983, 615.

NIKI, E. 1991. Vitamin C as an antioxidant. In Selected Vitamins, Minerals and Functional Consequences of Maternal Malnutrition. (Simopoulos, AP. ed.) 4, pp.1-3. World Rev. Nitr. Diet, Basel, Switzerland.

POKORNÝ, J. 1987. Major Factors Affecting the Autoxidation of Lipids. In: Autooxidation of unsaturated lipids. pp 141-206, ISBN 0-12-167630-7, Academic Press Inc, London. 
PRIBIL, R. 1972. Gravimetric Analysis. In Analytical Applications of EDTA and Relatated Compounds, (R. Pribil, ed.) pp. 63, 105. Pergamon Press, Oxford, UK. RAMANATHAN, L. and DAS, N.P. 1993. Effect of natural copper chelating compounds on the pro-oxidant activity of ascorbic acid in steam-cooked ground fish. J. Food Sci. Technol. 28, 279-288.

RICHARDS, M.P. and HULTIN, H.O. 2000. Effect of $\mathrm{pH}$ on lipid oxidation using trout hemolysate as a catalyst: a possible role for deoxyhemoglobin. J. Agric. Food Chem. $48,3141-3147$.

RICHARDS, M.P., ØSTDAL, H. and ANDERSEN, H.J. 2002. Deoxyhemoglobin-mediated lipid oxidation in washed fish muscle. J. Agric. Food Chem., 50, 1278-1283.

SIMPSON, G.R. and BLAY, R.A. 1966. Food Trade Review, August issue, 35-37.

THORARINSDOTTIR, K.A., ARASON, S., BOGASON, S.G. and KRISTBERGSSON, K. 2001. Effects of Phosphate on Yield, Quality, and Water-Holding Capacity in the Processing of Salted Cod (Gadus morhua). J. Food Sci. 66, 821-826.

VON HIPPEL, P.H. and SCHLEICH, T. 1969. The effects of neutral salts on the structure and conformational stability of macromolecules in solution. In: Structure and Stability of biological Macromolecules, (S.N. Timasheff and G.D. Fasman, eds) pp 417-574. Marcel Dekker, New York, NY.

WITTE, V.C., KRAUSE, G.T. and BAILEY, M.E. 1970. A new extraction method for determining 2-thiobarbituric acid values for pork and beef during storage. J. Food Sci. $35,582-585$.

AOAC Official Methods of Analysis 950.46, 11, 931. 1990. Moisture in Meat.

AOAC Official Methods of Analysis 937.09, 11, 870. 1990. Salt (Chlorine as Sodium chloride) in Seafood. 


\section{FIGURE LEGENDS}

FIG.1. LIPID OXIDATION IN SALT RIPENED COD. THE EFFECTS OF INCREASING ASCORBATE (0-2000 ppm) CONCENTRATIONS DURING BRINING WITHOUT COPPER ADDED. TBARS (2-thiobarbituric acid reactive substances), expressed as malondialdehyde (MDA) equivalents (--口--) and instrumental yellow color values, b*, (--•-

-) were measured at the end of the kench curing (21 days). Error bars represent mean standard deviations for pooled muscle samples $(\mathrm{N}=8)$ made from 30-40 cod fillets.

FIG.2. LIPID OXIDATION IN SALT RIPENED COD. THE EFFECTS OF INCREASING ASCORBATE CONCENTRATIONS WITH 5 ppm $\mathrm{Cu}^{2+}$ INCLUDED IN THE BRINE. (a): 0-200 ppm ascorbate $(\mathrm{N}=4-8),(\mathbf{b}): 200-2000 \mathrm{ppm}$ ascorbate $(\mathrm{N}=8)$. TBARS (2-thiobarbituric acid reactive substances), expressed as malondialdehyde (MDA) equivalents ( $\square$ - ) and instrumental yellow color values, $b^{*},(-\bullet-)$ were measured at the end of the kench curing (21 days). Error bars represent mean standard deviations for pooled muscle samples made from 20-40 cod fillets.

FIG.3. THE EFFECTS OF DIFFERENT ANTIOXIDANTS IN THE BRINES ON LIPID OXIDATION MEASURED AS TBARS (2-thiobarbituric acid reactive substances) (a) AND INSTRUMENTAL YELLOW COLOR VALUES (b) IN COD MUSCLE DURING 21 DAYS OF SALTING. Brines with 3 ppm $\mathrm{Cu}^{2+}$ added (-•-). Brines without $\mathrm{Cu}^{2+}$ added $(--\Delta-)$. Brines with 100 ppm ascorbate and 3 ppm $\mathrm{Cu}^{2+}$ added $(-\bullet-)$. Brines with $150 \mathrm{ppm}$ citrate and 3 ppm $\mathrm{Cu}^{2+}$ added (-Ж-). Brines with 193 ppm EDTA and 3 ppm $\mathrm{Cu}^{2+}$ added (一-). Mean TBARS, expressed as malondialdehyde (MDA) equivivalents, and mean 
instrumental color values, $b^{*}$, of pooled muscle samples $(\mathrm{N}=8)$ made from 30-40 cod fillets at each time of sampling.

FIG.4. THE COPPER CONTENT OF THE COD MUSCLE DURING SALT CURING WITH DIFFERENT ANTIOXIDANTS INCLUDED IN THE BRINE. Brines with 3 ppm $\mathrm{Cu}^{2+}$ added (-•-). Brines without $\mathrm{Cu}^{2+}$ added (-- $\left.\triangle--\right)$. Brines with $100 \mathrm{ppm}$ ascorbate and $3 \mathrm{ppm} \mathrm{Cu}{ }^{2+}$ added (-^). Brines with $150 \mathrm{ppm}$ citrate and $3 \mathrm{ppm} \mathrm{Cu}^{2+}$ added (一Ж-). Brines with 193 ppm EDTA and 3 ppm $\mathrm{Cu}^{2+}$ added (- - - Mean copper content of pooled muscle samples $(\mathrm{N}=8)$ made from $30-40$ cod fillets at each time of sampling.

FIG.5. THE pH (a), MOISTURE CONTENT (b) and NaCl CONTENT (c) OF THE COD MUSCLE DURING SALT CURING. EFFECTS OF DIFFERENT ANTIOXIDANTS AND COPPER IN THE BRINE. Brines with 3 ppm $\mathrm{Cu}^{2+}$ added (-॰-). Brines without $\mathrm{Cu}^{2+}$ added (-- $\Delta--)$. Brines with 100 ppm ascorbate and 3 ppm $\mathrm{Cu}^{2+}$ added (-^-). Brines with 150 ppm citrate and 3 ppm $\mathrm{Cu}^{2+}$ added (一Ж-). Brines with 193 ppm EDTA and 3 ppm $\mathrm{Cu}^{2+}$ added (-口-). Mean muscle $\mathrm{pH}$, moisture and $\mathrm{NaCl}$ content of pooled muscle samples $(\mathrm{N}=8)$ made from $30-40$ cod fillets at each time of sampling. 
Figure 1

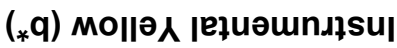

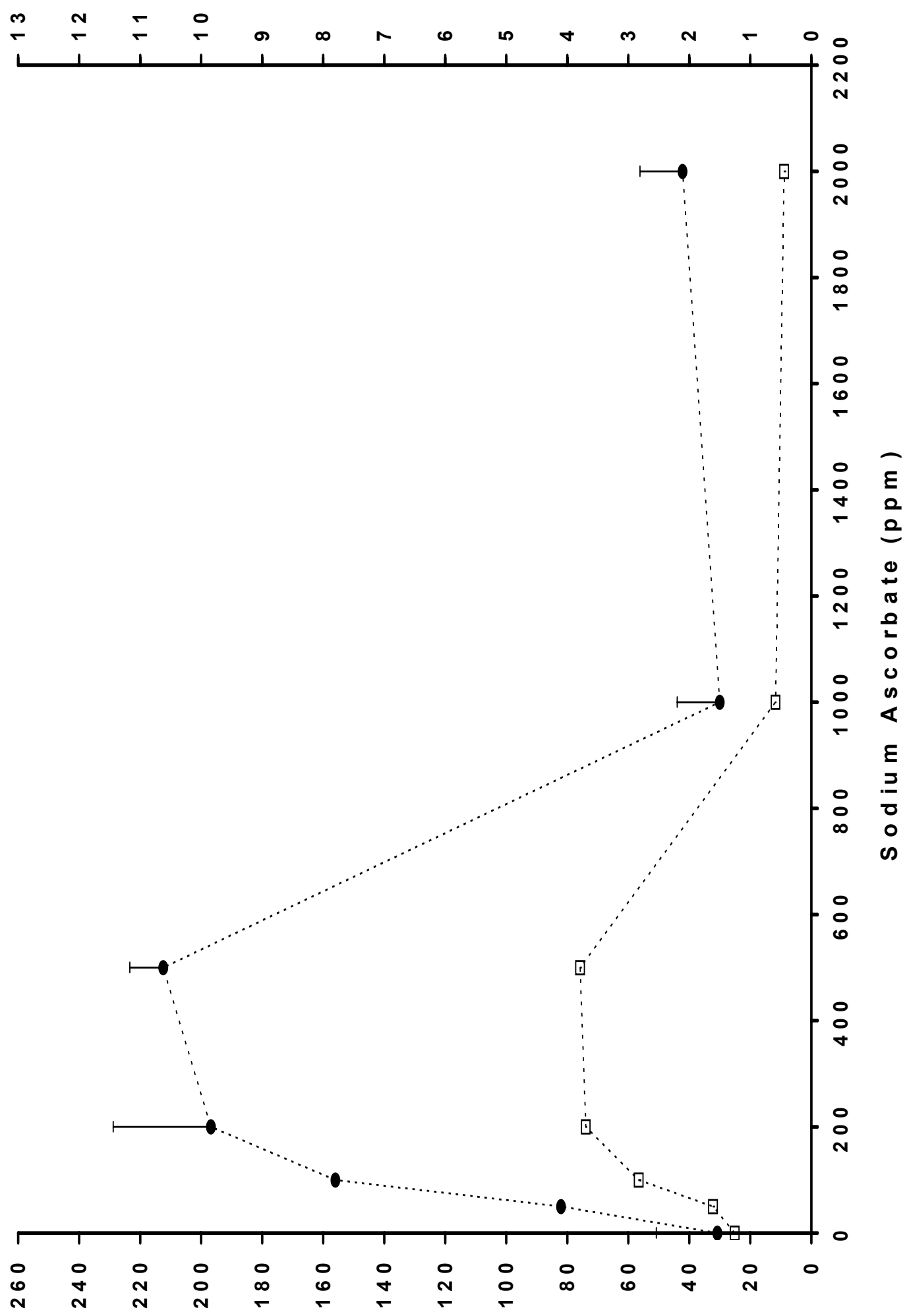

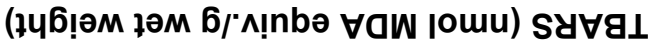


Figures 2 and $b$
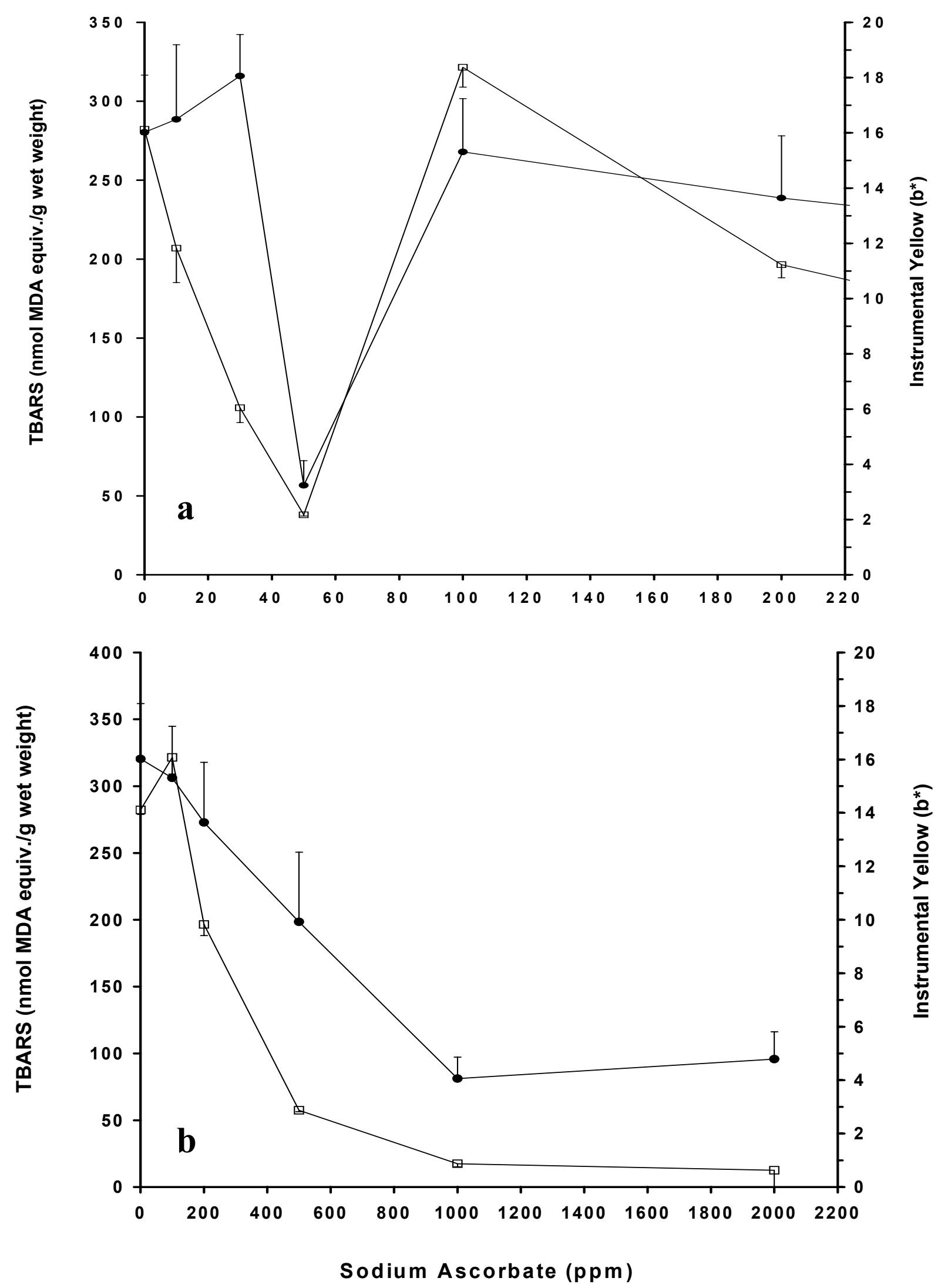
Figures 3 and $b$
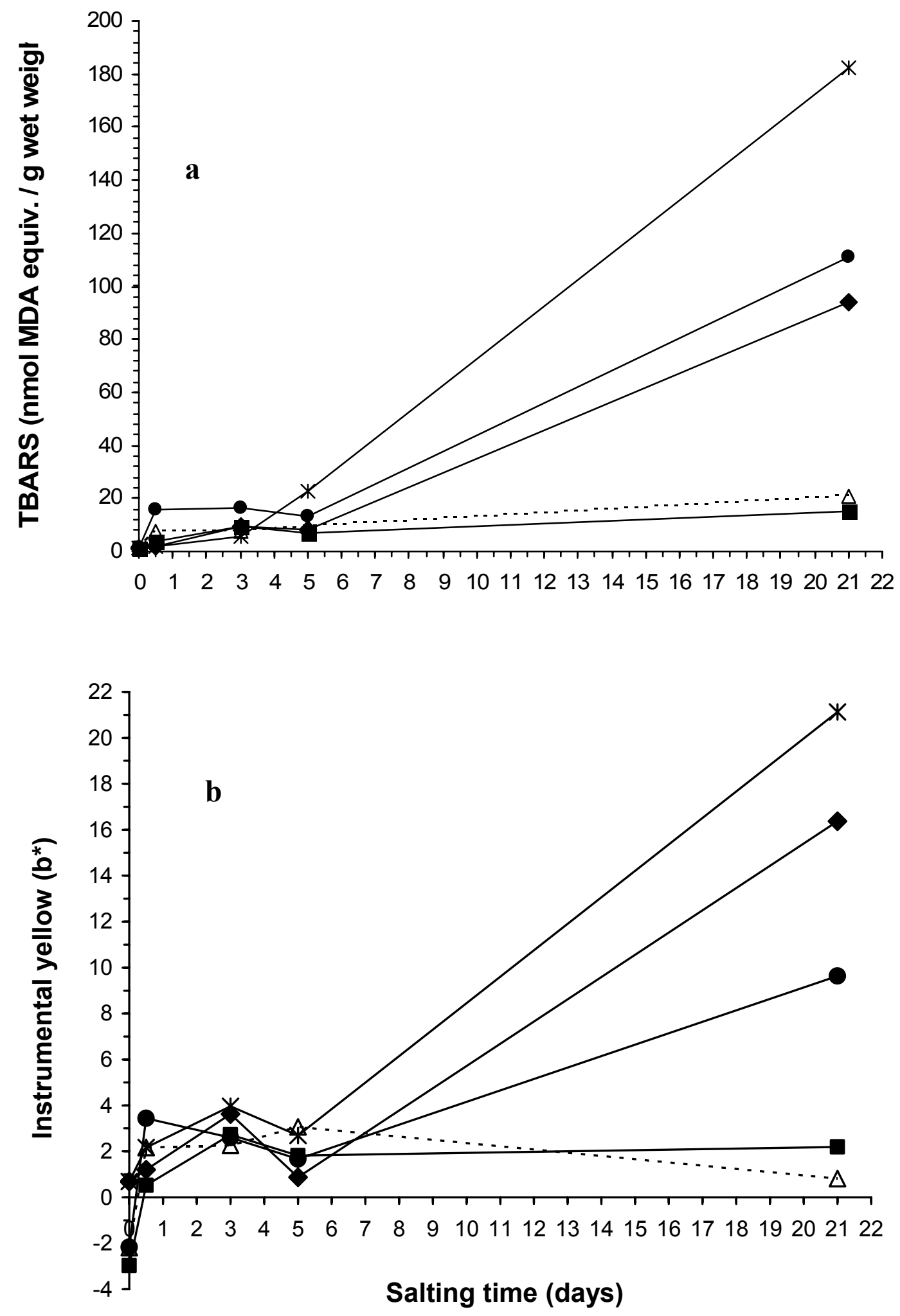
Figure 4

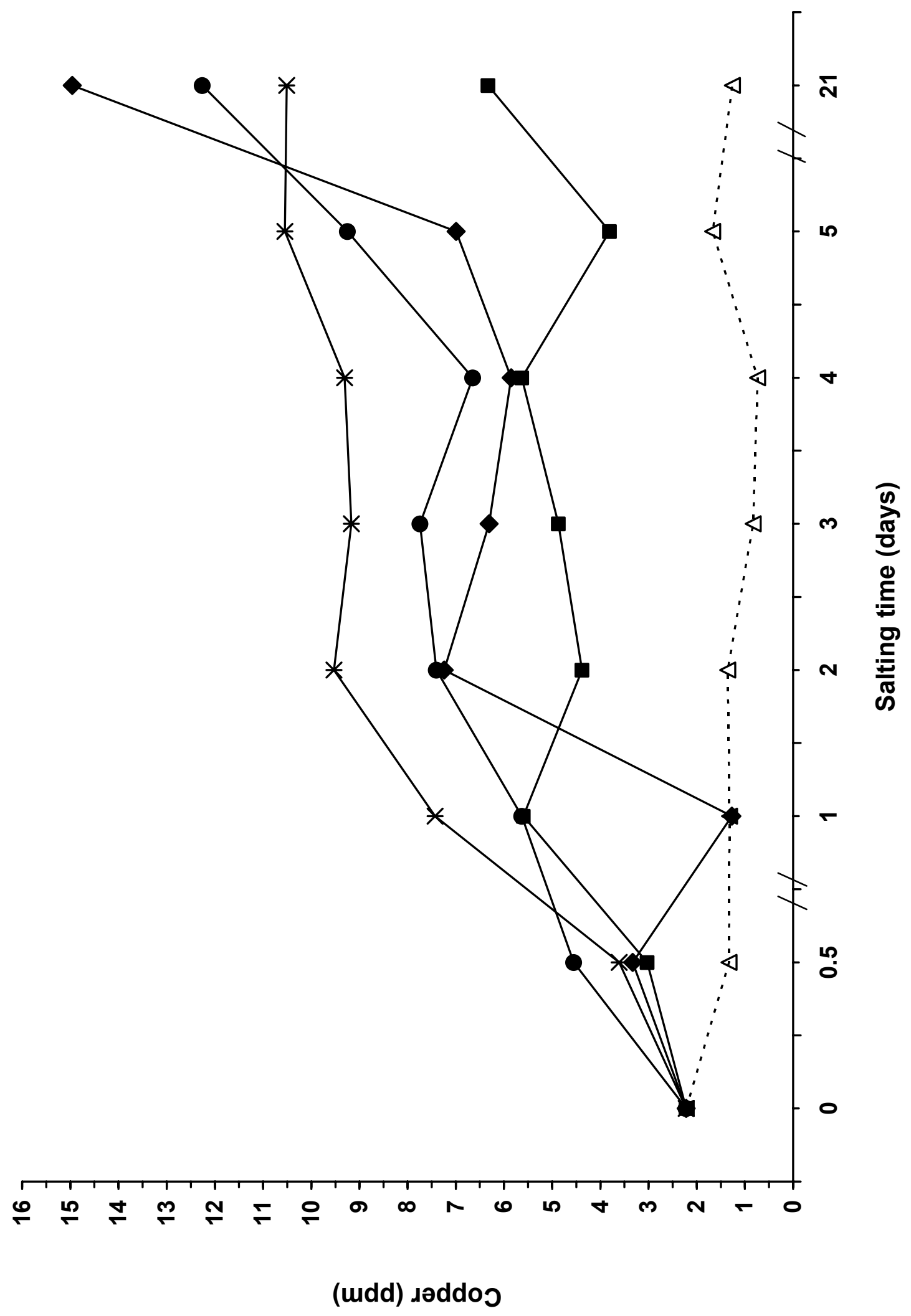


Figures 5 a, $b$ and $c$
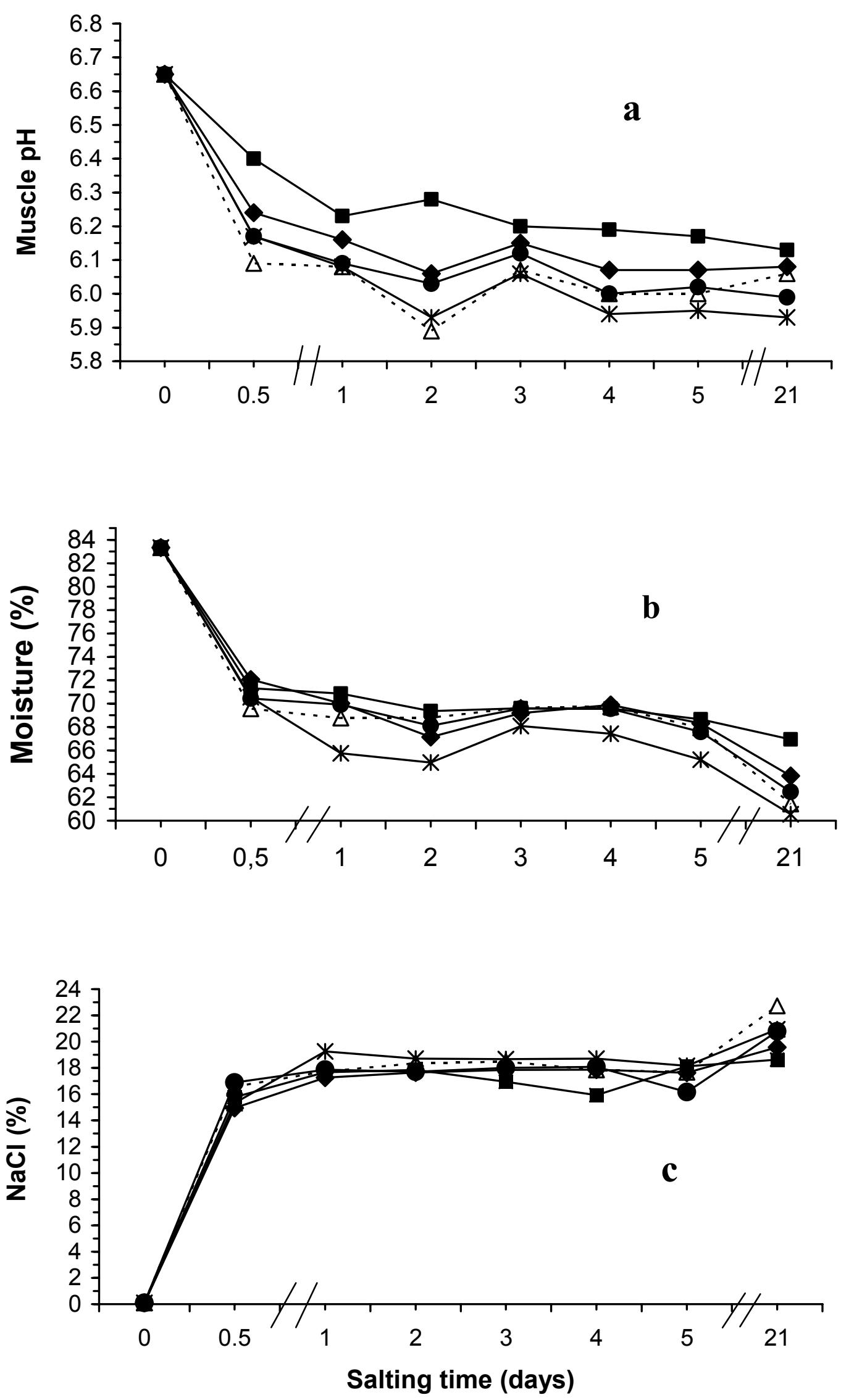